\title{
Digitalization AdOPTION AMONG MALAYSIAN SMES: THE DRIVERS AND ITS' INDUSTRY BASED HETEROGENEITY
}

\author{
Mei Peng, Low*
}

Department of International Business Universiti Tunku Abdul Rahman

Malaysia

lowmp@utar.edu.my

$$
\text { Hengky Latan }
$$

HLC Consluting

Indonesia

\section{Charbel J Chiappetta Jabbour}

Univeristy of Lincoln

United Kingdom

*Corresponding Author email: lowmp@utar.edu.my 


\section{A B S T R A C T}

Digital technologies advancement has immersed in many aspects of our lives, be it an individual or a business. The fast moving technologies has fostered the growth of digital economy. Businesses which fail to adopt will eventually lose their competitive advantage. The pressing phenomena motivates the study of digitalization adoption among small and medium enterprises (SMEs), which account for the majority of the businesses worldwide. Technology-Organization-Environment (TOE) framework was utilized to guide this study. The plausible difference between service based and non-service based industries was also examined. Quantitative approach via purposive sampling was performed to collect data from the SMEs. The data was analyzed using the concept of Hierarchical Component Model (HCM) for TOE constructs and Multi-Group Analysis (MGA) under the purview of Partial Least Square Structural Equation Modeling (PLS-SEM). For more insightful findings, Importance Performance Matrix Analysis (IPMA) was conducted. The findings informed that Technology and Organization record significant positive influence on Digitalization Adoption among SMEs while there is heterogeneity between service based and non-service based industries.

Keywords: Digitalization Adoption, SMEs, Technology-Organization-Environment (TOE) Framework, Hierarchical Component Models (HCM), Multi-Group Analysis (MGA)

\section{R E S E A R C H H I G H L I G H T S}

- The exponential progress of digital technologies has changed many aspects of our lives and business landscape. The advent digital technologies usage and adoption have flourished the growth of the digital economy. However, an important preliminary factor for a successful digital economy stem from the digitalization adoption among businesses.

- To gauge the achievement of the nation digital economy, it would be revealed from the digitalization adoption among companies. Businesses which fail to embrace digitalization will eventually face obsolescence.

- This research utilises firm-level approach, i.e., Technology-OrganizationEnvironment (TOE) framework to understand the digitalization adoption among Malaysian SMEs based on industry type.

- The data collected was analysed using PLS-SEM which entails Hierarchical Component Model (HCM), Multi-Group Analysis (MGA), and Importance Performance Matrix (IPMA).
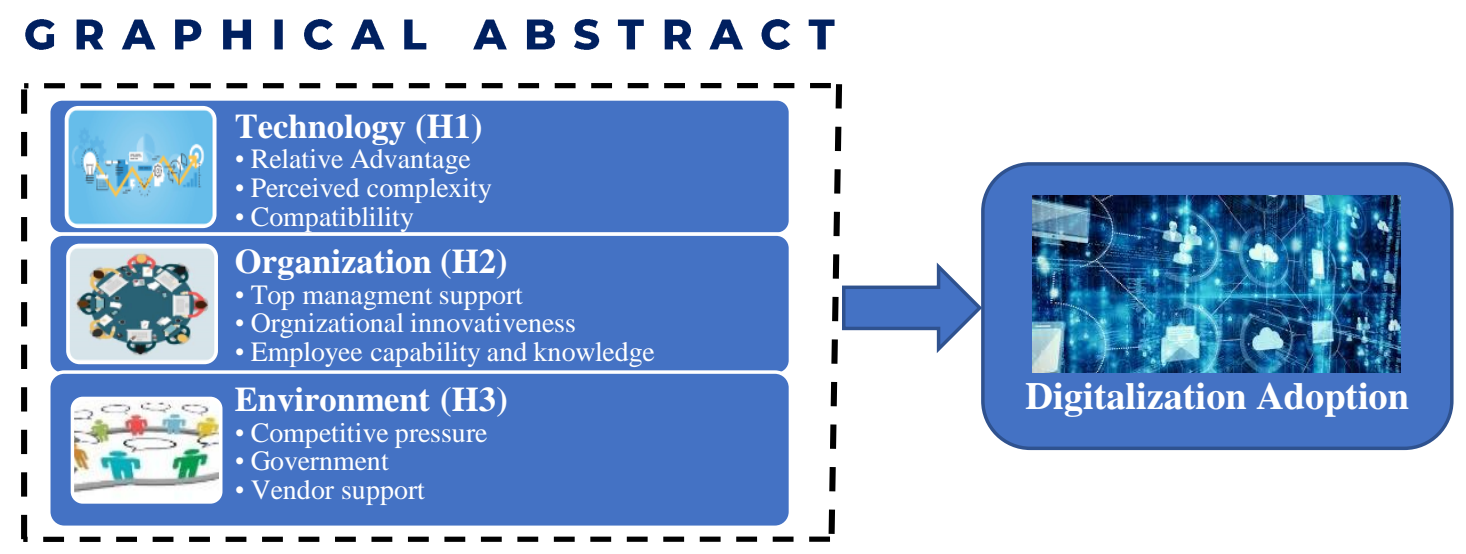

Fig. 1. Research framework to explore digitalization adoption 


\section{Research Objectives}

This research aims to study the Malaysian Small Medium-Sized Enterprises (SMEs)'s digitalization adoption through the Technology-Organization-Environment (TOE) framework. The research explores the relationships between Technology, Organization and Environment constructs toward digitalization adoption among SMEs. Acknowledging the differences between industries in term of their respective core competencies and capabilities, this research also examines the differences of digitalization adoption according to industry type. For more insightful findings, importance-performance matrix analysis (IPMA) is among the research objectives of this paper. IPMA is conducted with the objective to identify the most crucial element(s) for SMEs owners/ managers' attention in achieveing the digitalization adoption.

\section{Methodology}

This is a quantitive research. Questionnaire was used to collect data. The enterprise/ SME was the unit of analysis. Purposive sampling method was applied as a symmetrical sampling is not the main concern. Additionally, purposive sampling permits acquisition of focus sample within limited time frame. The TOE framework was modeled as a reflectiveformative HCM (Type II) (Becker, Klein, \& Wetzels, 2012), with Higher Order Component $(\mathrm{HOC})$ representing a more general construct of the reflectively measured Lower Order Component ( $L O C$ ). A repeated indicators approach was adopted to analyze HCMs for its ability to generate higher t-statistics as compared with other approaches (Duarte \& Amaro, 2018). MICOM assessment was performed before multi-group analysis (MGA) as recommended by Henseler, Ringle, and Sarstedt (2016). Importance-performance map analysis (IPMA) was carried out in order to identify the areas for improvement.

\section{Results}

For the reflectively measured LOC constructs, the results informed that internal consistency, convergent validity and discriminant validity were achieved. Meanwhile, the formatively measured HOC constructs had surpassed the requirements of the convergent validity, collinearity issues, significance and relevance of formative indicators (Ramayah, Cheah, Chuah, Ting, \& Memon (2016). For MICOM assessment, full measurement invariance was established for the service and non-service industry groups. In term of hypotheses testing, $\mathrm{H} 1$ and $\mathrm{H} 2$ are supported while $\mathrm{H} 3$ is not supported in the full sample and nonservice based industries sample. As for the service-based industries, only $\mathrm{H} 1$ is supported. In term of IPMA, among the reflectively measured LOC, compatibility, relative advantage and perceived compatibility are the most important constructs, and these are the predictors for technology. With regard to performances, top management support, relative advantage and employee capability and knowledge are ranked as the top three performing indicators. 


\section{Findings}

The findings informed that only Technology and Organization record significant positive influence on Digitalization Adoption among SMEs in Malaysia. The results reveal that there are differences between service based and non-service based industries. For service based industries, only Technology has a significant positive impact on Digitalization adoption, while for non-service based industry, both Technogym and Organization have positive impact on Digitalization adoption. SMEs shall emphasize on the Technology aspects particularly compatible, relative advantage and perceived compatibility for an effective digitalization adoption.

\section{Acknowledgement}

The authors would like to thank all the anonymous reviewers for their comments and suggestions.

\section{References}

Becker, J. M., Klein, K., \& Wetzels, M. (2012). Hierarchical latent variable models in PLS-SEM: guidelines for using reflective-formative type models, Long Range Planning, 45(5), 359-394.

Duarte, P., \& Amaro, S. (2018). Methods for modelling reflective-formative second order constructs in PLS: An application to online travel shopping, Journal of Hospitality and Tourism Technology, 9(3), 295-313.

Henseler, J., Ringle, C. M., \& Sarstedt, M. (2016). Testing measurement invariance of composites using partial least squares, International Marketing Review, 33(3), 405431.

Ramayah, T., Cheah, J., Chuah, F., Ting, H., \& Memon, M. A. (2016). Partial least squares structural equation modeling (PLS-SEM) using SmartPLS 3.0: An updated and practical guide to statistical analysis. Pearson.

\section{Author's Biography}

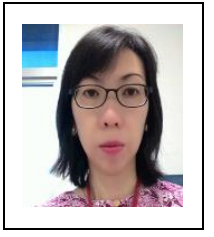

Mei Peng Low is an Assistant Professor in Universiti Tunku Abdul Rahman (UTAR), Malaysia. She holds a PhD in Organizational Behaviour. Before joining the academics, she was a consultant with PricewaterhouseCoopers Consulting Sdn Bhd. In her fifteen (15) years of academics, she has been actively involved in research work, paper publication, consultancy projects, and training. Her research focuses on employee-centred social responsibility, organizational behaviour, and digitalization. She has published numbers of international journals and presented in numerous international conferences. She also serves as the journal reviewer for a number of High Impact Journals. 